Research Article

\title{
Risk of metabolic syndrome in the first degree relatives of women with polycystic ovarian syndrome
}

\author{
Yashwant A. M. ${ }^{1}$, Prashant R. Kokiwar ${ }^{2}$, Gazala Taiseen $^{3}$
}

\author{
${ }^{1}$ Assistant Professor, Department of Community Medicine, Malla Reddy Institute of Medical Sciences, Suraram, \\ Telangana, India \\ ${ }^{2}$ Professor \& HOD, Department of Community Medicine, Malla Reddy Institute of Medical Sciences, Suraram, \\ Telangana, India \\ ${ }^{3}$ MBBS final year student, Malla Reddy Institute of Medical Sciences, Suraram, Telangana, India
}

Received: 18 September 2015

Accepted: 29 September 2015

\section{*Correspondence:}

Dr. Prashant R. Kokiwar,

E-mail: kokiwar@gmail.com

Copyright: (C) the author(s), publisher and licensee Medip Academy. This is an open-access article distributed under the terms of the Creative Commons Attribution Non-Commercial License, which permits unrestricted non-commercial use, distribution, and reproduction in any medium, provided the original work is properly cited.

\section{ABSTRACT}

Background: Poly cystic ovarian syndrome (PCOS) is a common disorder, affecting approximately $4-8 \%$ of women in the reproductive age group. First degree relatives (FDRs) of women with PCOS are at high risk developing endocrine and metabolic co-morbidities of PCOS such as obesity, insulin resistance (IR), and impaired insulin sensitivity, hyperlipidemia and metabolic syndrome (MBS). Present study was conducted with the objectives to evaluate the risk of metabolic syndrome in FDRs of women with PCOS and to compare the risk of metabolic syndrome in FDRs of women with PCOS with age, sex and relation matched FDRs of women with no PCOS. To give suitable recommendations based on the findings of the study.

Methods: Hospital based cross sectional analytical study was carried out. 50 FDRs of women with PCOS were compared against same number of age, sex and relation matched FDRs of women with no PCOS.

Results: The prevalence of MBS was significantly higher i.e. 34\% among FDRs $\mathrm{PCOS}_{\text {compared to FDRs }} \mathrm{Controls}_{\mathrm{s}}(8 \%)(\mathrm{p}$ $<0.05)$. The FDRs PCOS $_{\text {were }} 5.92$ times more at risk of MBS than FDRsControls $(\mathrm{p}<0.05)$. Relation wise it was found that the father $\mathrm{PCOS}_{\mathrm{PC}}$ and mother $_{\mathrm{PCOS}}$ were 1.5 times at risk, brother $\mathrm{PCOS}_{\text {were }} 14.26$ and sister PCOS $_{\text {were }} 12.43$ times at risk of MBS than their counterparts.

Conclusions: Thus it is concluded that the FDRs ${ }_{\mathrm{PCOS}}$ are at high risk of MBS than $\mathrm{FDRs}_{\mathrm{Controls}}$.

Keywords: Metabolic syndrome, Polycystic ovarian syndrome, Disorder, Obesity

\section{INTRODUCTION}

Poly cystic ovarian syndrome (PCOS) is a common disorder, affecting approximately $4-8 \%$ of women in the reproductive age group. ${ }^{1}$

The classic form of this syndrome includes amenorrhoea, anovulation, infertility, hirsutism, obesity and enlarged bilateral ovaries with cysts. There is an increased risk of diabetes mellitus (DM) and cardiovascular (CVS) diseases. In addition, insulin resistance (IR) and hyperinsulinaemia commonly occur. Lipoprotein abnormalities are also common in PCOS. Other PCOS complications include sleep apnoea and infertility. The high familial incidence of PCOS suggests its genetic origin. $^{2}$

In view of high prevalence of affected individuals within families of PCOS women, a genetic basis for this syndrome has been suggested. This has been evaluated in different population through phenotypic and family aggregation studies. ${ }^{3}$ 
First degree relatives (FDRs) of women with PCOS are at high risk developing endocrine ad metabolic comorbidities of PCOS such as obesity, IR, and impaired insulin sensitivity, hyperlipidaemia and metabolic syndrome. ${ }^{4}$

Abnormalities in insulin action and secretion, glucose tolerance, and lipid levels demonstrate familial aggregation in FDRs of women with PCOS. Elevated LDL cholesterol levels are the most consistent lipid abnormality in affected women as well as their sisters and mothers. In addition the prevalence of metabolic syndrome is increased in these groups. ${ }^{5}$

Keeping in view this increased risk of metabolic syndrome in FDRs of women with PCOS, we decided to study the risk of metabolic syndrome in FDRs of women with PCOS.

Early detection of metabolic syndrome in FDRs of women with PCOS is important as metabolic syndrome may predict a higher risk for CVS component. Hence early detection of metabolic syndrome can prevent the risk of CVS diseases in FDRs of women with PCOS. An opportunity for preventive health care exists and may alleviate risks for metabolic and CVS abnormalities in FDRs of women with PCOS.

With this idea, the present study was planned to compare the risk of metabolic syndrome in FDRs of women with PCOS with age, sex and relation matched controls in FDRs of women with no PCOS. This probably will help to establish that FDRs of women with PCOS are at high risk of developing metabolic syndrome.

Another reason that led us to consider to plan this study is that in our literature search of more than 50 studies on PCOS, there are very few studies from Asia and very rare of Indian origin.

Hence present study was undertaken with the main objective to study the risk of metabolic syndrome in FDRs of women with PCOS.

\section{METHODS}

\section{Study type and design}

Hospital based cross sectional analytical study.

\section{Study population}

FDRs of women with PCOS \& FDRs of women with no PCOS

\section{Place of study}

Malla reddy hospital which is attached to Malla Reddy Institute of Medical Sciences, Hyderabad, Telangana, India.

\section{Duration of study}

The study was conducted from January 2014 to October 2014.

\section{Sample size}

50 FDRs of women with PCOS were compared against same number of age, sex and relation matched FDRs of women with no PCOS.

\section{Selection criteria}

\section{A. For women with PCOS}

\section{Inclusion criteria}

Known cases of PCOS as diagnosed by Gynecologist

\section{Exclusion criteria}

1. Not willing to participate in the study.

B. For FDRs of women with PCOS.

\section{Inclusion criteria}

1. First degree relatives only

2. Not on treatment for DM, Hyperlipidemia and HT

\section{Exclusion criteria}

1. Not willing to participate

2. Seriously ill

C. For women with no PCOS

\section{Inclusion criteria}

1. No history of PCOS

2. Not on treatment for DM, Hyperlipidemia and HT

\section{Exclusion criteria}

1. Not willing to participate

2. History of PCOS in their families

3. Seriously ill

D. For FDRs of women with no PCOS.

Inclusion criteria

1. First degree relatives only

2. Not on treatment for DM, Hyperlipidemia and HT

\section{Exclusion criteria}

1. Not willing to participate

2. Seriously ill 


\section{Ethical considerations}

Institutional ethics committee permission was obtained. Informed consent was obtained from the women with PCOS and no PCOS as well as their FDRs if they are more than 18 years of age. If they are less than 18 years of age, then their mother's or father's consent was obtained. The study participants found at risk of metabolic syndrome, were given counseling and health education. Those with abnormal investigation reports were referred to the appropriate department for further management.

\section{Methodology}

Women with PCOS as diagnosed by Gynecologists were contacted. Necessary permission from the department was obtained. The nature of study was explained to women with PCOS. Confidentiality was ensured. They were asked to come with their FDRs on a fixed day early morning with 8-10 hours of fasting. The FDRs were included only if they satisfied the selection criteria.

The socio-demographic information, anthropometry and blood pressure were recorded in a pre-designed questionnaire. Then their blood samples were collected by the laboratory technician to be analyzed for lipid profile and fasting glucose. The blood samples were sent to the hospital laboratory and reports were collected.

The study subjects were contacted and asked to collect their reports. At this point of time, they were informed about the risk of metabolic syndrome and CVS diseases based on the reports. Health education was given with respect to adoption of healthy life styles and its importance; nutrition education and its importance. Those with abnormal reports were referred to endocrinologist.

The control group included age, sex and relation matched FDRs of women with no PCOS. A confirmation that these women do not have PCOS was obtained from the Gynecologist. Same procedure as mentioned above for experimental group was followed for this group also.

Metabolic syndrome was defined as follows:

The expert panel on detection, evaluation and treatment of high blood cholesterol in adults (Adult Treatment Panel III [ATP III]) recently published a consensus definition on insulin resistance syndrome (also termed as metabolic syndrome) based on abnormality in three or more of five component traits as follows. ${ }^{6}$
1. Abdominal obesity (waist circumference)
a. Men $>102 \mathrm{~cm}$
b. Women $>88 \mathrm{~cm}$
2. Blood pressure $>130 />85 \mathrm{mmHg}$
3 . Triglycerides $>150 \mathrm{mg} / \mathrm{dl}$
4. HDL Cholesterol
a. Men $<40 \mathrm{mg} / \mathrm{dl}$

b. Women $<50 \mathrm{mg} / \mathrm{dl}$

5 . Fasting glucose $>110 \mathrm{mg} / \mathrm{dl}$

Height was measured with the help of a height rod. The person was asked to remove shoes or chappals. The height was measured to the nearest of $0.5 \mathrm{~cm}$. For recording weight, the weight machine was standardized. It was ensured that it is kept on a flat and firm surface with its arrow on zero mark every time. The person was asked to stand with minimum clothing and without shoes or chappals. The weight was recorded to the nearest of $0.5 \mathrm{~kg}$. Based on height and weight, body mass index (BMI) was calculated as weight in $\mathrm{kg}$ divided by height in square meter.

Measurement of waist circumference was done with the help of a measuring tape as per the World Health Organizations (WHO) guidelines. ${ }^{7}$ Subjects were considered to have abdominal obesity if waist circumference was more than or equal to $102 \mathrm{~cm}$ in males and more than or equal to $88 \mathrm{~cm}$ in females. ${ }^{6}$

After a rest for a while, blood pressure (BP) was measured with the help of a sphygmomanometer in sitting position, putting the sphygmomanometer at the level of the heart. The procedure for recording BP was followed as per the WHO guidelines. ${ }^{8}$ As per this, three readings were obtained at an interval of five minutes and the lowest reading was recorded. For classifying the BP measurement, classification given by WHO was adopted. $^{8}$

Investigations like fasting glucose and lipid profile \{total cholesterol (TC), triglycerides (TG), and low density lipoproteins (LDL), high density lipoproteins (HDL)\} was done.

\section{Sample collection and methods of estimation}

The blood samples $(5 \mathrm{ml})$ were collected by venipuncture of cubital vein. For accurate comparison, fasting morning serum samples were obtained. The blood samples were collected in a plain redtop venipuncture tube without additives or anti-coagulants for preparation of serum. The blood was allowed to clot for serum samples. The specimens were centrifuged to separate the serum from the cells and analyzed for Triglycerides (TG), Total cholesterol (TC), HDL cholesterol (HDL-C), LDL cholesterol (LDL-C) by the following methods:

\section{Estimation of fasting glucose}

Fasting glucose was determined by GOD-POD method.

\section{Estimation of serum HDL-C}

Serum HDL-C was estimated by direct method using Jeev diagnostic kit. The system utilizes a combination of surfactants, phosphoric acid, organic acids, and inorganic acids, specifically binding LDL-C, VLDL-C and 
chylomicrons. Only HDL cholesterol was detected by the enzymatic CHOD/ POD method. ${ }^{9}$

\section{Estimation of Serum Triglycerides}

Serum triglyceride was estimated by Glycerol phosphate oxidase/ Peroxidase (GPO/POD) colorimetric endpoint method using Jeev diagnostic kit. Triglyceride was hydrolyzed by lipoprotein lipase to free fatty acids and glycerol. Glycerol kinase converts glycerol to glycerol phosphate, which gets oxidized to dihydroxy acetone phosphate and hydrogen peroxide by glycerol phosphate oxidase. Hydrogen peroxide so formed reacts with 4amino antipyrine in the presence of peroxidase to give a purple colored complex which is read at $505 \mathrm{~nm}$.

\section{Calculation of LDL-C}

LDL-C is obtained using Friedwald's formula as given below: ${ }^{10}$

LDL-C $=$ Total cholesterol $-($ HDL-C + VLDL-C $)$.
TG $>150 \mathrm{mg} / \mathrm{dl}$, HDL $<40 \mathrm{mg} / \mathrm{dl}$ in women and $<50$ $\mathrm{mg} / \mathrm{dl}$ in men, LDL $>160 \mathrm{mg} / \mathrm{dl}$ was considered as abnormal. ${ }^{6}$

\section{Statistical analysis}

The data was entered in Microsoft Excel Work Sheet and analyzed using proportions, chi square test, students' " $\mathrm{t}$ " test and Odds Ratio wherever applicable.

\section{RESULTS}

A hospital based cross sectional case control study was carried out to study the risk of metabolic syndrome among FDRs of women with PCOS. For all descriptive purposes, the first degree relatives of women with PCOS will be termed as FDR $_{\mathrm{PCOS}}$ [Fathers PCOS $_{\text {, Mothers }}$ PCOS, Brothers ${ }_{\mathrm{PCOS}}$ and Sisters $\left.\mathrm{PCOS}\right]$ and first degree relatives of women with no PCOS will be termed as controls [Father ${ }_{\text {Controls, }}$ Mother ${ }_{\text {Controls, }}$ Brothers Controls $_{\text {and }}$ Sisters $\left.{ }_{\text {Controls }}\right]$.

Table 1: Prevalence of metabolic syndrome among cases and controls.

\begin{tabular}{|c|c|c|c|c|c|c|}
\hline FDRPCOS & & & & trols & & \\
\hline $\begin{array}{l}\text { Metabolic } \\
\text { Syndrome }\end{array}$ & Male & Female & Total & Male & Female & Total \\
\hline Yes & $08(32)$ & $09(36)$ & $17(34)$ & $02(08)$ & $02(08)$ & $04(08)$ \\
\hline No & $17(68)$ & $16(64)$ & $33(66)$ & $23(92)$ & $23(92)$ & $46(92)$ \\
\hline Total & $25(100)$ & $25(100)$ & $50(100)$ & $25(100)$ & $25(100)$ & $50(100)$ \\
\hline
\end{tabular}

* Figures in the parentheses indicate percentages

Maximum study subjects were in the age group of 15-24 years (48\% FDR $_{\mathrm{PCOS}}$ and $46 \%$ controls). Minimum were in the age group of $45-54$ years. Very few study subjects were illiterate i.e. a total of $9 \%$. (14\% of FDR $_{\mathrm{PCOS}}$ and $4 \%$ controls). $38 \%$ of study subjects were educated more than Intermediate. Only $2 \%$ of study subjects were unemployed. $22 \%$ were home maker and $33 \%$ were students. No one was found belonging to class V. Only $4 \%$ belonged to class IV. Distribution of study subjects in social classes I to III is almost similar ranging from $30-35 \%$. This is because; they were matched for relation with index case. Maximum FDRs are brothers $(35 \%)$ followed by sisters $(28 \%)$ and mothers $(26 \%)$. Fathers are only $11 \%$. Prevalence of metabolic syndrome (MBS) is shown in table 1. The prevalence of MBS among FDR $_{\mathrm{PCOS}}$ is $34 \%$ compared to only $8 \%$ among controls. Among male FDR $_{\mathrm{PCOS}}$ it is $32 \%$ compared to $8 \%$ controls and among female FDR $_{\text {PCOS, it is } 36 \%}$ compared to $8 \%$ controls. Table 2 shows the risk of MBS in FDR $_{\text {PCOS }}$ which is the main objective of the present study. As also mentioned in table 1 , the prevalence of MBS among FDR $_{\mathrm{PCOS}}$ is $34 \%$ compared to only $8 \%$ among controls. This difference is found to be statistically significant. (Chi square $=10.2, \mathrm{p}=0.001$ ). It is observed that, the $\mathrm{FDR}_{\mathrm{PCOS}}$ are 5.92 times more likely to develop MBS than their counterparts. And this risk is also found statistically significant. $(\mathrm{Z}=2.962, \mathrm{p}=$ 0.0031).

Table 2: Risk of metabolic syndrome in first degree relatives of women with PCOS.

\begin{tabular}{|llll|}
\hline & $\begin{array}{l}\text { Metabolic } \\
\text { Syndrome } \\
\text { Present }\end{array}$ & $\begin{array}{l}\text { Metabolic } \\
\text { Syndrome } \\
\text { Absent }\end{array}$ & Total \\
\hline FDRPCOS & $17(34)$ & $33(66)$ & $50(50)$ \\
\hline Controls & $04(08)$ & $46(92)$ & $50(50)$ \\
\hline Total & $21(21)$ & $79(79)$ & $100(100)$ \\
\hline
\end{tabular}

* Figures in the parentheses indicate percentages $\mathrm{X} 2=10.2 ; \mathrm{df}=1 ; \mathrm{p}=0.001 ;$ Odds Ratio $=5.9242 ; 95 \%$ C.I. $=$ $1.8251-19.2299 ; \mathrm{Z}=2.962 ; \mathrm{p}=0.0031$.

Table 3 shows clinical and biochemical characteristics in brothers pCos and brother ${ }_{\text {Controls }}$ Mean age, anthropometric and blood pressure characteristics are almost similar in both the groups $(p>0.05)$. Among biochemical mean 
values, FBG, HDL, LDL, and TC are significantly more among brothers $\mathrm{PCOS}_{\mathrm{S}}$ than brother $_{\text {Controls. }}$

Table 4 shows clinical and biochemical characteristics in mothers PCOS and mother $_{\text {Controls. Among all the }}$ characteristics studied, only BMI is found to be significantly higher among mothers $\mathrm{PCOS}$ than mother $_{\text {Controls }}$ $(\mathrm{p}<0.05)$. For all other characteristics, the difference of mean is not found to be significant $(\mathrm{p}>0.05)$.

Table 3: Clinical and biochemical characteristics in Brother ${ }_{\mathrm{PCOS}}$ and Brother $_{\text {Controls. }}$

\begin{tabular}{|c|c|c|c|c|}
\hline & Brother PCos (18) & Brother $_{\text {Controls }}(17)$ & $\mathbf{T}$ & p \\
\hline & Mean \pm SD & Mean \pm SD & & \\
\hline Age & $21.44 \pm 4.24$ & $21.41 \pm 4.37$ & 0.0344 & 0.9728 \\
\hline BMI & $22.42+4.10$ & $21.02+2.99$ & 1.1484 & 0.2591 \\
\hline WC & $85 \pm 12.83$ & $78.88 \pm 9.93$ & 1.5714 & 0.1256 \\
\hline SBP & $116.44 \pm 11.55$ & $11.76 \pm 6.35$ & 1.4729 & 0.1503 \\
\hline DBP & $80 \pm 7.66$ & $75.29 \pm 7.17$ & 1.8753 & 0.0696 \\
\hline FBG & $97.38 \pm 14.47$ & $86.47 \pm 9.10$ & 2.6516 & 0.012 \\
\hline Triglycerides & $129.61 \pm 37.3$ & $129.76 \pm 54.99$ & 0.0095 & 0.9925 \\
\hline HDL & $37.11 \pm 4.6$ & $29 \pm 7.936$ & 3.7273 & 0.0007 \\
\hline LDL & $119.27 \pm 41.11$ & $87.47 \pm 43.88$ & 2.2137 & 0.0339 \\
\hline VLDL & $24.72+80.48$ & $25.58 \pm 11.09$ & 0.2586 & 0.7975 \\
\hline $\mathrm{TC}$ & $228 \pm 44.38$ & $151.23 \pm 40.89$ & 5.3131 & 0.0001 \\
\hline
\end{tabular}

$\mathrm{BMI}=$ body mass index, $\mathrm{WC}=$ waist circumference, $\mathrm{DBP}=$ diastolic blood pressure, $\mathrm{SBP}=$ systolic blood pressure, $\mathrm{FBG}=$ fasting blood glucose, HDL=high density lipoproteins, LDL=low density lipoproteins, VLDS=very low density lipoproteins, TC=total cholesterol

Table 4: Clinical and biochemical characteristics in Mother $_{\mathrm{PCOS}}$ and Mother ${ }_{\text {Controls. }}$

\begin{tabular}{|c|c|c|c|c|}
\hline & Mother $_{\mathrm{PCos}}(\mathbf{1 2})$ & Mother $_{\text {Controls }}(14)$ & $\mathbf{T}$ & $\mathbf{p}$ \\
\hline & Mean \pm SD & Mean \pm SD & & \\
\hline Age & $39.16 \pm 5.78$ & $39.71 \pm 6.79$ & 0.2203 & 0.8275 \\
\hline BMI & $25.53 \pm 5.41$ & $22.17 \pm 4.26$ & 2.0905 & 0.0473 \\
\hline WC & $82.25 \pm 17.92$ & $86.64 \pm 10.9$ & 0.7670 & 0.4505 \\
\hline SBP & $110.83 \pm 9$ & $115 \pm 6.5$ & 1.3683 & 0.1835 \\
\hline DBP & $74.16 \pm 9$ & $73.57 \pm 8.41$ & 0.1727 & 0.8644 \\
\hline FBG & $103.83 \pm 26.46$ & $108.7 \pm 68.77$ & 0.2007 & 0.8426 \\
\hline Triglycerides & $115.5 \pm 64.17$ & $164.14 \pm 89.87$ & 1.5624 & 0.1313 \\
\hline HDL & $38 \pm 5.84$ & $36.92 \pm 4.66$ & 0.5245 & 0.6047 \\
\hline LDL & $120.41 \pm 44.21$ & $134.85 \pm 38.48$ & 0.8909 & 0.3819 \\
\hline VLDL & $26.58 \pm 16.98$ & $32.85 \pm 17.78$ & 0.9150 & 0.3692 \\
\hline $\mathrm{TC}$ & $182.08 \pm 46.04$ & $204.28 \pm 37.16$ & 1.3609 & 0.1862 \\
\hline
\end{tabular}

$\mathrm{BMI}=$ body mass index, $\mathrm{WC}=$ waist circumference, $\mathrm{DBP}=$ diastolic blood pressure, $\mathrm{SBP}=$ systolic blood pressure, $\mathrm{FBG}=$ fasting blood glucose, HDL=high density lipoproteins, LDL=low density lipoproteins, VLDS=very low density lipoproteins, TC=total cholesterol

Table 5 shows clinical and biochemical characteristics in fathers PCOS $_{\text {and }}$ father ${ }_{\text {Controls. The difference of mean }}$ values between fathers ${ }_{\mathrm{PCOS}}$ and father $\mathrm{Controls}_{\mathrm{s}}$ in all studied parameters is statistically not significant $(p>0.05)$ except mean HDL $(\mathrm{P}<0.05)$.

Table 6 shows clinical and biochemical characteristics in sister $\mathrm{PCOS}_{\text {and }}$ sister $_{\text {Controls. }}$ Only mean value of FBG is significantly higher in sister $_{\mathrm{PCOS}}$ than $\operatorname{sister}_{\text {Controls }}(\mathrm{p}<$ 0.05 ). Difference in mean of all other characteristics is statistically not significant $(\mathrm{p}>0.05)$.

\section{DISCUSSION}

The present study was conducted with the objective to study the risk of metabolic syndrome (MBS) in FDRs of 
women with PCOS. They were compared with age, sex and relation matched FDRs of women with no PCOS.

For all descriptive purposes, the first degree relatives of women with PCOS will be termed as FDR PCOS (Fathers ${ }_{\mathrm{PCOS}}$, Mothers ${ }_{\mathrm{PCOS}}$, Brothers ${ }_{\mathrm{PCOS}}$ and Sisters PCOS $_{\text {) }}$ and first degree relatives of women with no PCOS will be termed as controls (Father $_{\text {Controls, }}$ Mother ${ }_{\text {Controls, }}$, Brothers $_{\text {Controls }}$ and Sisters Controls $_{\text {) }}$.

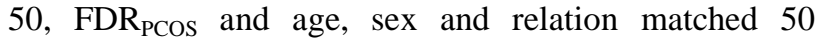
controls were studied.

We found that the prevalence of MBS was very high among FDR $_{\mathrm{PCOS}}$ i.e. $34 \%$ whereas among controls, it was only $8 \%$. This difference was statistically significant. $\left(\mathrm{X}^{2}\right.$ $=10.2, p=0.001)$. Similarly, the risk of MBS was 5.9 times more for $\mathrm{FDR}_{\mathrm{PCO}}$ than controls. This risk is also found statistically significant $(\mathrm{Z}=2.962, \mathrm{p}=0.0031)$.

Table 5: Clinical and biochemical characteristics in father $_{\mathrm{PCOS}}$ and father ${ }_{\mathrm{Controls} .}$

\begin{tabular}{|c|c|c|c|c|}
\hline & father ${ }_{P C O S}(6)$ & father ${ }_{\text {Controls }}(5)$ & $\mathbf{t}$ & $\mathbf{p}$ \\
\hline & Mean \pm SD & Mean \pm SD & & \\
\hline Age & $46.33 \pm 6.59$ & $45.6 \pm 7.09$ & 0.1769 & 0.8635 \\
\hline BMI & $23.20 \pm 2.85$ & $23.35 \pm 4.49$ & 0.0675 & 0.9477 \\
\hline WC & $81.66 \pm 21.07$ & $87 \pm 15.93$ & 0.4656 & 0.6526 \\
\hline SBP & $123.33 \pm 5.16$ & $120 \pm 7.07$ & 0.9040 & 0.3896 \\
\hline DBP & $83.33 \pm 10.32$ & $80 \pm 0$ & 0.7149 & 0.4928 \\
\hline FBG & $104.16 \pm 9.43$ & $93.4 \pm 13.14$ & 1.5822 & 0.1481 \\
\hline Triglycerides & $118.16 \pm 34.85$ & $157 \pm 43.25$ & 1.6711 & 0.1290 \\
\hline HDL & $40 \pm 5.93$ & $33 \pm 2.64$ & 2.4299 & 0.0380 \\
\hline LDL & $126 \pm 41.08$ & $122 \pm 43.15$ & 0.1572 & 0.8785 \\
\hline VLDL & $25 \pm 10.27$ & $31 \pm 8.86$ & 1.0248 & 0.3322 \\
\hline $\mathrm{TC}$ & $184.66 \pm 44.86$ & $186 \pm 39.22$ & 0.0536 & 0.9548 \\
\hline
\end{tabular}

$\mathrm{BMI}=$ body mass index, $\mathrm{WC}=$ waist circumference, $\mathrm{DBP}=$ diastolic blood pressure, $\mathrm{SBP}=$ systolic blood pressure, $\mathrm{FBG}=$ fasting blood glucose, HDL=high density lipoproteins, LDL=low density lipoproteins, VLDS=very low density lipoproteins, TC=total cholesterol

Table 6: Clinical and biochemical characteristics in sister $_{\mathrm{PCOS}}$ and sister $_{\text {Controls. }}$

\begin{tabular}{|lllll|}
\hline & \multicolumn{1}{c}{ sister $_{\text {Pcos }}(\mathbf{1 4})$} & sister $_{\text {Controls }}(\mathbf{1 4})$ & T & P \\
\hline Age & \multicolumn{1}{c|}{ Mean \pm SD $^{\text {SD }}$} & $21.85 \pm 4.31$ & 0.3831 & 0.7048 \\
\hline BMI & $22.64 \pm 6.40$ & $18.17 \pm 2.92$ & 0.9367 & 0.3575 \\
\hline WC & $19.35 \pm 3.7$ & $78 \pm 11.3$ & 0.5387 & 0.5947 \\
\hline SBP & $75.42 \pm 13.91$ & $105 \pm 5.18$ & 1.7050 & 0.1001 \\
\hline DBP & $110.71 \pm 11.41$ & $68.57 \pm 9.49$ & 1.9052 & 0.0679 \\
\hline FBG & $76.42 \pm 12.15$ & $85.57 \pm 6.42$ & 2.2477 & 0.0333 \\
\hline Triglycerides & $94.21 \pm 12.87$ & $139.21 \pm 62.17$ & 1.0770 & 0.291 \\
\hline HDL & $118.14 \pm 38.64$ & $32.21 \pm 4.44$ & 2.0022 & 0.0558 \\
\hline LDL & $36.14 \pm 5.85$ & $97.42 \pm 25.65$ & 1.5285 & 0.1385 \\
\hline VLDL & $112.92 \pm 27.96$ & $27.5 \pm 12.42$ & 1.0243 & 0.3153 \\
\hline TC & $23.5 \pm 7.6$ & $157.14 \pm 24.37$ & 1.5132 & 0.1423 \\
\hline
\end{tabular}

Shabir I et al also reported from Kashmir that the prevalence of MBS was $22 \%$ among FDR $_{\text {PCOS. }}$. Akbarzadeh et al also observed a high prevalence of MBS as $29.35 \%$ in fatherspcos compared to only $8.8 \%$ of fathers of women in the control group. ${ }^{2,11}$
These findings suggest that the high prevalence of MBS in $\mathrm{FDR}_{\mathrm{PCOS}}$ is due to familial aggregation.

We observed that, the prevalence of MBS was $50 \%$ in fathers PCOS $_{\text {and }} 40 \%$ in father Controls. 
Shabir I et al revealed very high prevalence i.e. $56 \%$. Coviello et al observed that the prevalence of MBS was $42 \%$ in fathers ${ }_{\text {PCOS }}$ and $32 \%$ in father Controls. $^{11,12}$ Akbarzadeh et al observed that the prevalence of MBS

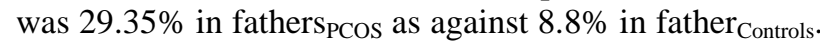
Gabrielli L et al reported prevalence of diabetes (DM) and impaired glucose tolerance (IGT) as $27 \%$ and $31 \%$ among father ${ }_{\mathrm{PCOS}} \cdot{ }^{2,13}$

Prevalence of MBS is $41.6 \%$ in mother $_{\mathrm{PCOS}}$ compared to $14.28 \%$ in mother $_{\text {Controls }}$ in the present study.

Shabir I et al reported almost double i.e. $80 \%$ prevalence

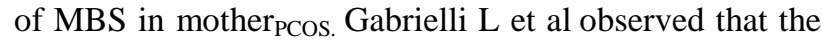
prevalence of DM \& IGT was $16 \%$ and $30 \%$ respectively in mother ${ }_{\mathrm{PCOS}}$, and that of impaired fasting glucose (IFG) was $3 \%$ in mother ${ }_{\text {PCOS. }}{ }^{11,13}$

In the present study, among brother ${ }_{\mathrm{PCOS}}$ the prevalence of MBS was $27.7 \%$ compared to nil among brother ${ }_{\text {Controls. }}$

But Shabir I et al did not find any brother ${ }_{\mathrm{PCOS}}$ with MBS. Whereas Coviello et al observed this rate as $22 \%$ in brother $_{\text {PCOS }}$ compared to only $9 \%$ among brother Controls. Gabrielli L et al found no DM in brother $_{\mathrm{PCOS}}$ but IFG was present in $4 \%$ of brother $_{\text {PCOS. }}{ }^{11-13}$

We observed that the prevalence of MBS in sister ${ }_{\mathrm{PCOS}}$ was $28.57 \%$ and no case of MBS in sister Controls. .

Shabir I et al also reported that $25 \%$ of $\operatorname{sister}_{\mathrm{PCO}}$ were having MBS. Bulent $\mathrm{O}$ et al found no DM in sister $\mathrm{PCOS}$ but reported that prevalence of IGT was $5 \% .^{11,13}$

In the present study, we compared the mean values of clinical and biochemical parameters among FDR $_{\mathrm{PCOS}}$ and FDR ${ }_{\text {Controls }}$

For brothers, we found that FBG, HDL, LDL \& TC mean values were significantly higher in brother $_{\mathrm{PCOS}}$ than brother ${ }_{\text {Controls. }}$ But the difference in mean values of all other parameters was not significant statistically $(\mathrm{p}>$ 0.05). ${ }^{5}$ Susan Sam et al found that SBP was similar among brother ${ }_{\mathrm{PCOS}}$ and brother $\mathrm{C}_{\mathrm{Controls}}$ but the difference in DBP was significant. Akbarzadeh et al found no statistically significant difference for blood pressure which is similar to our findings. ${ }^{14}$ Susan Sam et al reported no significant difference of mean BMI and WC and we also observed the same. ${ }^{5}$ But Shabir I et al reported a prevalence of $73.6 \%$ of $\mathrm{BMI}>23 \mathrm{~kg} / \mathrm{m}^{2}$ in brother $_{\mathrm{PCOS}}{ }^{11}$ Likewise, Coviello $\mathrm{AD}$ et al also found higher BMI in brother ${ }_{\mathrm{PCOS}}{ }^{12}$ For brother $_{\mathrm{PCO}}$ we found that mean value of TC, LDL, HDL\& FBG is significantly higher. Susan Sam et al also reported that the mean value of TC, LDL higher, similar to our study but TG was also higher in brother ${ }_{\mathrm{PCOS}}$ which is not significantly higher in the present study. ${ }^{5}$ For HDL, they found no significant difference. Shabir I et al observed that TG $\geq 150 \mathrm{mg} / \mathrm{dl}$ was present in $42 \%$ of brother ${ }_{\text {PCOS. }}{ }^{11}$ Similar to our study findings, Murat $\mathrm{Y}$ et al also reported that difference in mean of age, BMI, WHR, SBP, DBP was not significant and that of TC, LDL was significant for brothers. ${ }^{15}$

Mean difference in clinical and biochemical characteristics for mothers in the present study revealed that except higher significant BMI value in mother ${ }_{P C O S}$, all other characteristics were similar for mother ${ }_{\mathrm{PCO}}$ and mother ${ }_{\text {Controls. Akbarzadeh found that the average blood }}$ pressure was high among mother ${ }_{\mathrm{PCOS}}{ }^{14} \mathrm{SBP}>130 \mathrm{mmHg}$ and DBP $>85 \mathrm{mmHg}$ was present in $47 \%$ each of mother ${ }_{\mathrm{PCO}}$ in a study by Shabir I et al. ${ }^{11}$ They also found that the prevalence of BMI $>23 \mathrm{~kg} / \mathrm{m}^{2}$, fasting glucose $>100 \mathrm{mg} / \mathrm{dl}$, and $\mathrm{TG} \geq 150 \mathrm{mg} / \mathrm{dl}$ was $95.4 \%, 12 \%$ and $76 \%$ respectively. Murat $\mathrm{Y}$ et al revealed that age, BMI, HDL mean value were not significantly different but mean WHR, SBP, DBP, TC, LDL, TG were significantly higher in mother ${ }_{\mathrm{PCOS}}{ }^{15} \mathrm{He}$ also found that prevalence of glucose intolerance was $40 \%$ among mother ${ }_{\mathrm{PCOS}}$.

For fathers, all characteristics were almost similar ( $p>$ 0.05) except HDL, which was significantly higher among father ${ }_{\mathrm{PCOS}}$.

Whereas Murat $\mathrm{Y}$ et al reported that except age and BMI, all other characteristics were significantly higher in father $_{\text {PCOS. }}{ }^{15}$ Akbarzadeh $M$ et al revealed that average blood pressure was significantly more in father ${ }_{\mathrm{PCOS}} 14$ Shabir I et al reported that the prevalence of SBP $>130$ $\mathrm{mmHg}$, DBP >85 mmHg, BMI > $23 \mathrm{~kg} / \mathrm{m}^{2}$, IFG >100 $\mathrm{mg} / \mathrm{dl}, \mathrm{TG} \geq 150 \mathrm{mg} / \mathrm{dl}$, was $45 \%, 45 \%, 82.6 \%, 20 \%$, and $65 \%$ respectively among father $_{\text {PCos. }}{ }^{11}$ Akbarzadeh et al also reported that $14.7 \%$ of father PCOS $_{\text {were hypertensive }}$ and $29.4 \%$ were diabetics and $17.6 \%$ had high total cholesterol levels. $^{2}$ Coviello AD et al ${ }^{12}$ found higher BMI

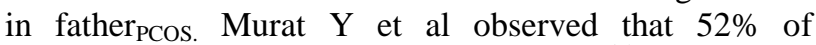
father $_{\text {PCOS }}$ were having glucose intolerance. ${ }^{15}$

In the present study, among sisters, only mean FBG was significantly higher among sister ${ }_{\mathrm{PCOS}}$ than sister ${ }_{\text {Pontrols. }}$ All other characteristics mean was not significantly different. Murat $\mathrm{Y}$ et al also found that age, BMI, WHR, SBP, DBP, TC, LDL, HDL, TG were similar for $\operatorname{sister}_{\mathrm{PCOS}}$ and sister $_{\text {Pontrols }}$ and this finding is similar to our study. ${ }^{15}$ But Akbarzadeh et al found that average blood pressure was higher in sister ${ }_{\mathrm{PCOS}}{ }^{11}$ Shabir I et al reported the prevalence of $\mathrm{SBP}>130 \mathrm{mmHg}$, DBP > $85 \mathrm{mmHg}$, BMI > 23 $\mathrm{kg} / \mathrm{m}^{2}, \mathrm{IFG}>100 \mathrm{mg} / \mathrm{dl}, \mathrm{TG} \geq 150 \mathrm{mg} / \mathrm{dl}$, as $15 \%, 15 \%$, $77.2 \%, 12 \%$, and $45 \%$ respectively for sister $_{\text {PCOS. }}{ }^{14}$

Thus from the present study, it is clear that the FDRs $s_{\text {PCOS }}$ are at high risk of having MBS than their counterparts. Some findings in the present study are not found to be significant, especially when the comparison was made between individual relationships. This may be due to a very small sample of fathers etc. But jointly, when compared with controls, FDRs $s_{\mathrm{PCO}}$ are significantly at high risk of MBS. 


\section{CONCLUSION}

It was found that the prevalence of metabolic syndrome among FDRsPCOS is significantly very high i.e. $34 \%$ vs $8 \%$ in FDRsControls. The risk of MBS is significantly high for brothers ${ }_{\mathrm{PCOS}}$ and sisters $\mathrm{PCOS}_{\text {but not for }}$ fathers PCOS $_{\text {and mothers }}$ acos. This study warrants further research into prevalence of MBS and other androgenic abnormalities among FDRsPCOS. This will help establish that screening should be carried out for FDRs of women who are diagnosed as having PCOS in any hospital.

\section{ACKNOWLEDGEMENTS}

We are thankful to Indian Council of Medical Research (ICMR) who has provided us opportunity to carry out this study through ICMR STS Programme.

\section{Funding: No funding sources}

Conflict of interest: None declared

Ethical approval: The study was approved by the Institutional Ethics Committee

\section{REFERENCES}

1. Yildiz BO, Yarali H, Oguz H, Bayraktar M. Glucose intolerance, insulin resistance and hyperandrogenemia in first degree relatives of women with polycystic ovary syndrome. J ClinEndocrinolMetab. 2009;88(5):2031-6.

2. Akbarzadeh M, Moradi F, Dabbaghmanesh MH, Jafari P, Parsanezhad ME. A survey of metabolic syndrome in first degree relaties (fathers) of patients with polycystic ovarian syndrome. J EndocrinolMetab and Diabetes of South Africa. 2013;18(2):98-103.

3. Recabarren SE, Smith R, Rios R, Maliqueo M, Echiburu B, Codner E et al. Metabolic profile in sons of women with polycystic ovary syndrome (PCOS). J ClinEndocrinolMetab. 2008;93(5):18206.

4. Raissouni N, Kolesnikov A, Purushothaman R, Sinha S, Bhandari S, Bhangool A et al. Altered glucose disposition and insulin sensitivity in peripubertal first degree relatives of women with polycystic ovary syndrome. Int J PediatrEndocrinol. 2012;2012(1):14.

5. Sam S, Coviello AD, Sung Ya, Legro RS, Dunaif A. Metabolic phenotype in the brothers of women with polycystic ovary syndrome. Diabetes Care. 2008;31(6):1237-41.

6. Pankow JS, Jacobs DR, Steinberger J. Insulin resistance and cardiovascular disease risk factors in children of parents with the insulin resistance (metabolic) syndrome. Diabetes Care. 2004;27:77580.

7. World Health Organization: Physical status: The use and interpretation of anthropometry: WHO Tech Rep Series. 1995;854:424-38

8. Park K. Park's Textbook of Preventive and Social Medicine. $21^{\text {st }}$ edition, M/s BanarasidasBhanot Publishers, Jabalpur, 2005.

9. Kimberly MM, Leary ET, Cole TG, Waymack PP. Selection, Validation, Standardization, and Performance of a Designated Comparison Method for HDL-Cholesterol for Use in the Cholesterol Reference Method Laboratory Network. Clinical Chemistry. 1999;45:1803-12.

10. Friedewald WT, Levy RI, Fredrickson DS. Estimation of the concentration of low-density lipoprotein cholesterol in plasma, without use of the preparative ultracentrifuge. Clin Chem. 1972;18(6):499-502.

11. Shabir I, Ganie MA, Zargar MA, Bhat D, Mir MM, Jan A, et al. Prevalence of metabolic syndrome in the family members of women with polycystic ovary syndrome from North India. Indian $\mathbf{J}$ EndocrinolMetab. 2014;18(3):364-9.

12. Coviello AD, Sam S, Legro RS, Dunaif A. High prevalence of Metabolic syndrome in first-degree male relatives of women with Polycystic ovary syndrome is related to high rates of obesity. J Clin Endocrinal Metab. 2009;94:4361-6.

13. Gabrielli L, AquinoEstela ML. Polycystic ovary syndrome in Salvador, Brazil:a prevalence study in primary healthcare.Reproductive Biology and Endocrinology2012;10:96. Available at: http://www.rbej.com/content/10/1/96.

14. Akbarzadeh M, Moradi F, Dabbaghmanesh MH, Jafari P, Parsanezhad ME. Abnormal blood pressure and hyperandrogenemia in first degree relatives ofwomen with polycystic ovarian syndrome referring to gynecology clinics of Shiraz Medical University. International Journal of Obstetrics and Gyanecology. 2014;2(2):40-4.

15. Murat Y, Bukan M, ErsoyR, Karakoc A, Yetkin I, Ayvas $G$ et al. Glucose intolerance, insulin resistance and cardiovascular risk factors in firstdegree relatives of women with polycystic ovary syndrome. Human Reproduction. 2005;20(9):241420.

Cite this article as: Yashwant AM, Kokiwar PR, Taiseen G. Risk of metabolic syndrome in the first degree relatives of women with polycystic ovarian syndrome. Int J Community Med Public Health 2015;2:441-8. 